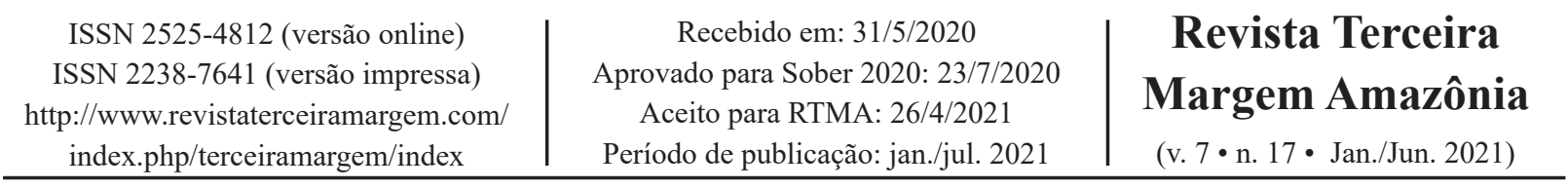

Como citar o artigo:

GARCIA, R. J.; ROMEIRO, A. R. Agricultura brasileira: desafios frente a restrição ambiental. Revista Terceira Margem Amazônia, v. 7, n. 17, p. 33-53, 2021. DOI: http://dx.doi.org/10.36882/2525-4812.2021v7i17.p33-53

\title{
AGRICULTURA BRASILEIRA: DESAFIOS FRENTE A RESTRIÇÃO AMBIENTAL
}

\author{
Junior Ruiz Garcia ${ }^{1}$ \\ Ademar Ribeiro Romeiro ${ }^{2}$
}

\begin{abstract}
Resumo: O desenvolvimento da agricultura brasileira pode ser caracterizado pela incorporação contínua de novas terras. Um sinal de mudança nessa dinâmica ocorre a partir da institucionalização do Paradigma do Desenvolvimento Sustentável. Contudo, ainda persiste o avanço da fronteira agrícola, mas agora amparado pelo uso intensivo de capital e tecnologia. Nesse contexto, o objetivo principal deste estudo é explorar a dinâmica agricultura e meio ambiente no Brasil a partir de uma perspectiva econômico-ecológica e histórica. $\mathrm{O}$ estudo adota uma abordagem qualitativa-exploratória, mas acompanhada de dados estatísticos, a fim de reforçar a análise da agricultura e sua interface ambiental no Brasil. Apesar do avanço tecnológico e das práticas de manejo no Brasil, não há sinais de reversão da tendência de degradação ambiental, ameaçando a sustentabilidade de longo prazo da agricultura.
\end{abstract}

Palavras-chave: fronteira agrícola, inovação, desenvolvimento sustentável, agronegócio.

\section{BRAZILIAN AGRICULTURE: CHALLEN2GES IN FRONT OF ENVIRONMENTAL RESTRICTION}

\begin{abstract}
The development of Brazilian agriculture can be characterized by the continuous incorporation of new lands. A sign of change in this dynamic comes from the institutionalization of the Sustainable Development Paradigm. However, the advance of the agricultural frontier still persists, but now supported by the intensive use of capital and technology. In this context, the main goal of this work is to explore the dynamics of agriculture and the environment in Brazil from an economic-ecological and historical perspective. The study adopts a qualitative-exploratory approach, but accompanied by statistical data in order to reinforce the analysis of agriculture and its environmental interface in Brazil. Despite technological advances and management practices in Brazil, there are no signs of reversing the trend of environmental degradation, threatening the long-term sustainability of agriculture.
\end{abstract}

Keywords: agricultural frontier, innovation, sustainable development, agribusiness.

\footnotetext{
1 Economista, doutor em Desenvolvimento Econômico, professor da Universidade Federal do Paraná (UFPR), Curitiba, PR. E-mail: jrgarcia@ufpr.br

(D) http://orcid.org/0000-0002-9625-3859

2 Economista, doutor em Economia, professor da Universidade Estadual de Campinas, Campinas, SP. E-mail: arromeiro@gmail.com

(D) http://orcid.org/0000-0003-0683-3030
} 


\section{Introdução}

A trajetória histórica do desenvolvimento agrícola brasileiro, ao longo de 5 séculos, tem sido caracterizada por uma incorporação contínua e predatória de novas terras ((IBGE, 2020; PETRUCCELLI, 1994; PROJETO MAPBIOMAS, 2020). Com exceção da cultura da cana ${ }^{3}$, o modelo agrícola brasileiro, até a segunda metade do século XX, baseava-se na produção itinerante - desmatamento, queima, cultivo por 2 ou 3 anos, abandono da terra, novo desmatamento, queima e assim por diante. A princípio, o objetivo era fornecer alimentos para garantir a segurança alimentar da população brasileira. Mas, em um segundo momento, a agricultura assume o papel de fornecedora de mão de obra para a industrialização (BUAINAIN et al., 2014; CANO, 1998; FURTADO, 1980).

Um sinal de mudança nessa dinâmica ocorre a partir da institucionalização do Paradigma do Desenvolvimento Sustentável (BRANDENBURG et al., 2013; NOBRE; AMAZONAS, 2002), mas ainda persiste o avanço da fronteira agrícola (IBGE, 2020). Contudo, o modelo agrícola intensivo em tecnologia e capital do século XXI tem alterado gradualmente essa dinâmica (BRANDENBURG et al., 2013; GASQUES et al., 2019; GIULIANI, 1997; MEDINA, 2019; ROMEIRO, 2014; VIEIRA FILHO; GASQUES, 2016). Apesar do avanço tecnológico da agricultura, não há reversão da tendência de degradação ambiental, ameaçando a sua sustentabilidade de longo prazo.

A moderna agricultura foi impulsionada por uma lógica econômica que promove produção intensiva em recursos naturais, capital e tecnologia, com impactos ambientais até então considerados imprevisíveis (BALSAN, 2006; BITTENCOURT, 2009, 2010). Mas essa agricultura pode ser orientada pela abordagem dos serviços ecossistêmicos (MILLENIUM ECOSYSTEM ASSESSMENT BOARD, 2003; PRADO et al., 2016; ZHANG et al., 2007), que usa a dinâmica do ecossistema para trabalhar para a produção agrícola.

Nesse contexto, o objetivo principal deste estudo é explorar a dinâmica agricultura e meio ambiente no Brasil a partir de uma perspectiva econômico-ecológica e histórica. O estudo adota uma abordagem qualitativa-exploratória, mas acompanhada de dados estatísticos, a fim de reforçar a análise da agricultura e sua interface ambiental no Brasil. A pesquisa conta com levantamento bibliográfico e consulta às bases de dados agropecuários do Instituto Brasileiro de Geografia e Estatística (IBGE), da Organização das Nações Unidas para a Agricultura, FAOSTAT (FAO - Food and Agriculture Organization of the United Nations), do Ministério da Agricultura, Pecuária e Abastecimento (Mapa), da Federação Brasileira dos Produtores de Plantio Direto e Irrigação (FEBRAPDP), entre outras.

O trabalho está organizado em três seções, além desta introdução e das considerações finais. Na primeira seção, explora-se a relação entre serviços ecossistêmicos e agricultura. Na segunda, discute-se a dinâmica histórica entre o crescimento da agricultura brasileira e o meio ambiente. Por fim, na terceira, analisam-se os desafios e soluções para uma agricultura ecológica no Brasil.

\footnotetext{
Como será visto mais abaixo, por suas características morfológicas, a cultura da cana protege o solo contra a erosão. O café, por sua vez, embora seja uma cultura perene, protege menos o solo e foi cultivado durante muito tempo sem curva de nível, o que facilitou em muito os processos erosivos, forçando o abandono da área após um certo número de anos.
} 


\section{Serviços ecossistêmicos e a agricultura: algumas reflexões}

Os relatórios da Avaliação Ecossistêmica do Milênio (MILLENNIUM ECOSYSTEM ASSESSMENT BOARD, 2003) ${ }^{4}$ contribuíram para consolidar e divulgar a importância dos serviços ecossistêmicos (SEs) para o bem-estar e para a economia. Um resultado prático da Avaliação Ecossistêmica do Milênio foi a inclusão da temática na agenda política e o incentivo para o desenvolvimento de pesquisas em SEs, com destaque para a abordagem baseada em serviços ecossistêmicos (DAILY, 1997; MILLENNIUM ECOSYSTEM ASSESSMENT BOARD, 2003; PARRON et al., 2019; ZHANG et al., 2007).

Os SEs são benefícios que a sociedade (e a economia) obtém direta ou indiretamente dos ecossistemas, como água potável, controle de erosão, polinização, alimentos e combustível, amenidade climática, entre outros (DAILY, 1997; DE GROOT et al., 2002; MILLENNIUM ECOSYSTEM ASSESSMENT BOARD, 2003; STEGER et al., 2018). Esse entendimento não é recente; Platão, por exemplo, já visualizava a relação entre a cobertura florestal e o controle de processos erosivos e mesmo a ocorrência de secas (MOONEY; EHRLICH, 1997).

Os SEs têm sido agrupados em serviços de suporte, regulação, provisão e socioculturais (MILLENNIUM ECOSYSTEM ASSESSMENT BOARD, 2003) (Figura 1). Os serviços de suporte são responsáveis por assegurar o fluxo dos demais SEs, enquanto estes afetam diretamente o bem-estar. A importância dos demais SEs para o bem-estar pode ser resumida em: suporte à vida, garantia do fluxo de recursos naturais renováveis e não renováveis, manutenção da relativa estabilidade climática, assimilação de resíduos, fonte de informação (DAILY, 1997; DE GROOT et al., 2002; DOMINATI et al., 2010; MILLENNIUM ECOSYSTEM ASSESSMENT BOARD, 2003). O provimento de SEs, portanto, requer o envolvimento humano.

Figura 1. Serviços ecossistêmicos e o bem-estar.

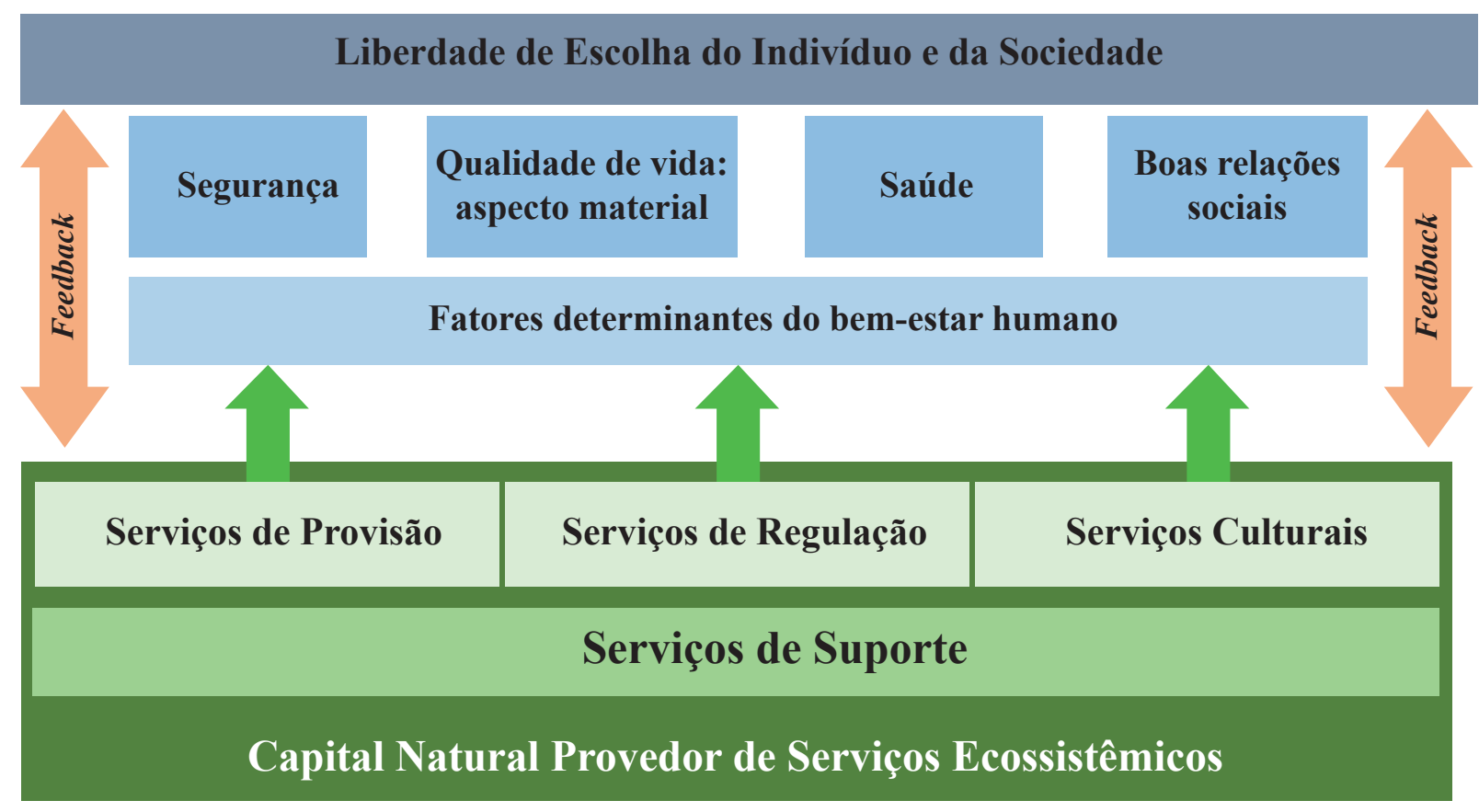

Fonte: Elaborado pelos autores com base em Millennium Ecosystem Assessment Board (2003).

4 O objetivo foi avaliar o efeito das mudanças no ecossistema para o bem-estar. Essa iniciativa foi realizada de 2001 a 2005 ,
envolvendo mais de 1.360 especialistas em todo o mundo. Ver www.millenniumassessment.org 
Na perspectiva dos SEs, a produção agropecuária deveria ser entendida como um SE, cuja origem é um agroecossistema manejado pelo agricultor (PARRON et al., 2019; SWIFT et al., 2004; ZHANG et al., 2007). Os sistemas agropecuários correspondem a ecossistemas manejados pela sociedade. As práticas de manejo adotadas por produtores rurais podem aumentar ou reduzir o fluxo de SEs (KROEGER; CASEY, 2007; PARRON et al., 2019; ZHANG et al., 2007). Fora da propriedade, por exemplo, a agricultura pode contribuir para o controle de cheias a partir da permeabilidade do solo (KROEGER; CASEY, 2007). Dentro da propriedade, a agricultura pode ser beneficiada pelo SE de polinização realizada por polinizadores (SWIFT et al., 2004).

A evolução da agropecuária revela esse entendimento, uma vez que o objetivo central é maximizar o SE de provisão de alimentos, fibras e combustível a partir de agroecossistemas (SWIFT et al., 2004). A agropecuária é responsável pelo provimento de agro-ecosystem services (KROEGER; CASEY, 2007). No entanto, a maximização do SE de provisão tem sido acompanhada pela perda de SEs vitais para a sociedade e para a própria manutenção dos sistemas produtivos, como diversidade genética, controle de pragas e doenças e habitats (MILLENNIUM ECOSYSTEM ASSESSMENT BOARD, 2003; SWIFT et al., 2004), além de gerar externalidades negativas sob a forma de poluição química das águas, do solo, da fauna e da flora natural e dos alimentos (MILLENNIUM ECOSYSTEM ASSESSMENT BOARD, 2003; SWIFT et al., 2004; ZHANG et al., 2007).

$\mathrm{Na}$ verdade, os SEs que poderiam ser manejados dentro de um agroecossistema, de modo a manter a sustentabilidade da produção agropecuária, foram substituídos pelo capital produzido pela sociedade (MULDER et al., 2006), como fertilizantes, pesticidas, combustível, máquinas e equipamentos. Entretanto, ao contrário do que é ensinado nos manuais de economia ambiental (PEARCE; TURNER, 1990), não foi uma substituição perfeita, pois pode comprometer a própria capacidade de provisão de alimentos no longo prazo. É preciso ter claro que, para a sustentabilidade das práticas agrícolas, é fundamental ver a produção de alimentos e fibras como um SE, mas provido por um agroecossistema cuja dinâmica deve ser compreendida (ROMEIRO, 1991, 1998).

As práticas agrícolas modernas se desenvolveram baseadas em uma visão extremamente reducionista e irreal dos ecossistemas. Um exemplo desse reducionismo, que predominou por um período depois da descoberta de Liebig sobre a nutrição vegetal (ASSIS; ROMEIRO, 2002), foi a visão do solo como um simples reservatório de nutrientes e suporte para as plantas, cuja fertilidade poderia ser mantida indefinidamente pelo aporte de fertilizantes químicos. Com base em tal "modelo ecológico" do solo, um parâmetro de sustentabilidade como tolerância à perda de solos - taxa de erosão - praticamente perde sentido, podendo ser substituído pelo custo da fertilização química.

O avanço das pesquisas contribuiu para uma visão mais realista do solo, que passou a ser visto como um complexo ecossistema, com dinâmica própria, que deve ser respeitado e manejado, além de ser responsável por uma série de SEs. Nesse sentido, a erosão não somente reduz a quantidade de nutrientes do solo, mas degrada SEs, como a capacidade de estocagem de água, de estruturação adequada para o enraizamento das plantas, mobilização de nutrientes, entre outros. A monocultura, por exemplo, provoca um profundo desequilíbrio, tanto do ponto de vista da cobertura vegetal (infestações de pragas) como da estrutura física, química e biológica do solo. Essa 
simplificação do sistema produtivo pode ser evitada a partir da rotação de culturas (GONÇALVES et al., 2007; LUTZENBERGER, 2001; ROMEIRO, 1998), uma prática que, quando ecológica e tecnicamente orientada, pode contribuir para a estabilidade do agroecossistema. Além de reduzir o risco de infestação de pragas, as rotações contribuem para a manutenção de uma boa estrutura físico-química-biológica do solo. O estado do solo, em determinado momento, resulta de sua história cultural, isto é, das culturas e práticas adotadas. As rotações de culturas, por sua vez, têm por objetivo modelar essa história em um sentido favorável, isto é, o de favorecer as condições de abastecimento de água e de nutrientes para as plantas, bem como manter a fertilidade do solo no longo prazo (SEBILLOTTE; BOURGEOIS, 1978).

Nos sistemas agrícolas simplificados, sobretudo na monocultura de cereais, os fatores desestabilizadores ganham força, obrigando o agricultor a recorrer a técnicas mais intensivas em energia para manter as condições favoráveis ao desenvolvimento dos vegetais. Entretanto, essas soluções não eliminam as causas do desequilíbrio, apenas "contornam" seus efeitos de curto prazo sobre os rendimentos. Na década 1980, quando a modernização da agricultura francesa já havia se consolidado, Sebillotte (1982), reconhecido agrônomo e pesquisador francês, notava que as práticas ditas modernas buscavam adequar determinada parcela do solo a dada cultura para $o$ ano seguinte. Se preciso fosse, readequá-la para outra monocultura por meio de uma diversificada panóplia de possantes meios químicos e mecânicos, sem se importar se o efeito da cultura precedente é desfavorável ou não (MITCHELL, 1960).

A eficácia inicial desses meios químicos e mecânicos havia tornado a grande maioria dos especialistas extremamente otimista, levando-os a supor que os agricultores não mais teriam que se submeter aos princípios básicos da agricultura tradicional, especialmente a rotação de culturas. A perda dos benefícios da rotação de culturas poderia ser compensada, sem problemas, com os novos meios mecânicos e químicos, como tratores mais possantes e novos equipamentos de trabalho do solo (MITCHELL, 1960).

Contudo, a experiência mostrou que não é correto pensar em compensação dos efeitos nefastos por meio de técnicas e equipamentos. Ao contrário, desde os anos 1970, Remy e Marin Lafleche (1976) já observavam que, na França, em razão da baixa geral da taxa de matéria orgânica, a estrutura física dos solos tornara-se cada vez mais suscetível à ação de fatores climáticos, bem como à passagem de máquinas e equipamentos. Devido a esse desequilíbrio estrutural dos solos, vinha sendo introduzida uma série de procedimentos de reestruturação mecânica, que exigiam a passagem cada vez mais frequente de máquinas possantes e pesadas. $\mathrm{O}$ baixo teor de matéria orgânica, por exemplo, torna necessário um esforço maior de tração (máquinas mais possantes e pesadas) para trabalhos profundos de descompactação, que, por sua vez, têm forte impacto negativo sobre o solo.

A degradação da estrutura física do solo estava provocando constante contradição do ponto de vista das intervenções, que visava modificar favoravelmente as condições de abastecimento de água e de nutrientes para as plantas: quanto mais o solo se degrada, menos se pode contar com os SEs para se obter as condições necessárias para o cultivo, as quais têm que ser obtidas por meio de intervenções químico-mecânicas, consideradas degradantes. A degradação do agroecossistema, portanto, explica toda uma dinâmica de inovações, como novos procedimentos de uso de equipamentos e/ou novos equipamentos (PAPY, 1982). 
No que concerne aos insumos, a resistência adquirida aos tratamentos pelos diversos agentes patogênicos e pragas levou a uma trajetória de busca contínua por novos produtos. Na medida em que esse caminho vem sendo inviabilizado, seja pelos custos crescentes da pesquisa vis-à-vis aos resultados obtidos, seja pela crescente consciência ambiental da população, têm-se buscado soluções (ROMEIRO, 1998, 2014), como: substituição de pesticidas químicos por biológicos, desenvolvimento de espécies resistentes a pragas e doenças.

Além de contaminar o meio ambiente, os princípios ativos dos agrotóxicos perturbam a atividade biológica no interior dos solos, em geral já afetada pela queda da taxa de matéria orgânica e pelo excesso de trabalho mecânico. Essa dinâmica provoca alguns problemas, tais como dificuldades para a realização de uma fertilização equilibrada, particularmente no que se refere ao nitrogênio (ROMEIRO, 2014). Esse elemento mineral, por ser um aníon, não é retido pelo poder absorvente do solo, de modo que seu uso excessivo provoca vários problemas, entre os quais a poluição dos recursos hídricos.

Sebillotte (1975) estimava que o agricultor, mesmo cuidadoso, colocava mais nitrogênio do que o necessário, porque ele não tinha como controlar as "sobras" em fim de inverno. Se esse agricultor fizesse rotação de culturas, incorporasse os restos de cultura, cultivasse adubo verde e outras práticas ecologicamente mais equilibradas, não haveria problemas, pois o nitrogênio sobrante seria capturado pela microvida do solo. O paliativo agroquímico consiste em adicionar inibidores da desnitrificação e/ou usar compostos nitrogenados tamponados, de modo que sua liberação fosse lenta (fertilizantes a "retardamento").

Além desses paliativos, a indústria de fertilizantes desenvolveu fórmulas e formulações, como amononitratos, fosfato de amônia, polifosfatos, etc.; formas físicas, granulados, líquidos, gaseificados, em suspensão, etc.; técnicas de fertilização, fracionamento das dosagens, profundidade, etc. (BITTENCOURT, 2009). Os avanços em informática e sensoriamento remoto permitiram o desenvolvimento da "agricultura de precisão" (MOLIN, 2004): os tipos e as dosagens de nutrientes podem ser calculados para cada parcela de terra por um computador instalado no trator, o qual processa os dados sobre o solo, enviados por satélite. Desse modo, o desperdício é reduzido e, consequentemente, a poluição também.

Pode-se dizer que a evolução do padrão tecnológico que caracteriza as práticas agrícolas modernas foi condicionada, em grande medida, pela necessidade de "contornar" os impactos ecológicos negativos da monocultura (perda dos SEs). No entanto, a capacidade de contornar foi se esgotando, na medida em que as técnicas empregadas para isso são, em parte, degradantes delas próprias. No Brasil, esse cenário pode ser visualizado na redução dos ganhos de produtividade (GASQUES et al., 2019). Nesse sentido, tornou-se clara a necessidade de adoção, pelo menos, de princípios ecológicos.

A ideia básica é a de recuperar a racionalidade das práticas agrícolas tradicionais a partir de outra base de conhecimento científico e tecnológico. A aplicação da informática e da biotecnologia permite organizar e gerir sistemas de produção mais complexos, sem redução significativa da produtividade do trabalho (ROMEIRO, 2014). O que gerações de agricultores praticaram de modo intuitivo e empírico se revela à luz da ciência um importante conjunto de técnicas ecologicamente mais balanceadas, desenhadas para usar a natureza em benefício da produção 
(MAZOYER; ROUDART, 2010). Recuperar a lógica da gestão dos SEs do próprio agroecossistema é uma condição necessária para que a agricultura moderna volte a ter um horizonte de sustentabilidade multissecular.

A partir desse contexto, analisa-se, a seguir, a evolução da agropecuária brasileira e sua relação com o meio ambiente.

\section{O meio ambiente e a agricultura brasileira}

Nos primeiros séculos de colonização europeia, a maioria dos países colonizadores se limitou a controlar direta ou indiretamente a produção de produtos disponíveis nas regiões colonizadas. O Brasil foi a primeira colônia de um país europeu onde desde o início se organizou a produção de uma commodity agrícola, inexistente até então: o açúcar (CANO, 1998; FURTADO, 1980; PRADO JUNIOR, 1977). Os portugueses foram testando, desde a fronteira sul com o território espanhol ${ }^{5}$, onde poderiam produzir cana-de-açúcar e com isso garantir também um povoamento perto da fronteira.

Em São Vicente, litoral do estado de São Paulo, foi iniciada a produção de cana-de-açúcar (FURTADO, 1980; PRADO JUNIOR, 1977). Porém, não demorou muito para que os bons solos (massapés) litorâneos da região Nordeste do Brasil (SANTOS et al., 2006) se firmassem como a melhor opção. Esse tipo de solo é bastante apto para o cultivo de cana-de-açúcar, uma cultura semiperene, cuja forma de vegetação confere uma boa proteção do solo contra erosão (ROMEIRO, 1998). Por isso, por séculos, a região Nordeste se tornou o polo produtor de açúcar do Brasil (FURTADO, 1980; PRADO JUNIOR, 1977).

Uma trajetória distinta teve a segunda mais importante commodity agrícola do Brasil, que começaria a ser explorada a partir do começo do século XIX: o café (CANO, 1998; FURTADO, 1980). A expansão inicial da produção no Vale do Paraíba deixou um rastro de destruição dos solos (ROMEIRO, 1998). O café foi plantado sem curvas de nível nas colinas que dominam a paisagem da região, em poucas décadas destruiu o horizonte superficial, já não muito profundo, dos solos ali predominantes.

Nesse sentido, durante um longo período, ao contrário da cana-de-açúcar, o café foi itinerante no País, devido à destruição que provocava aos solos. Essa dinâmica era movida por razões distintas das praticadas pelos indígenas e caboclos (derrubada e queimada). Nos sistemas agrícolas baseados na derrubada-queimada, os solos são cultivados por 1, 2 ou até 3 anos, na sequência um pousio de longa duração, entre 10 e 50 anos (MAZOYER; ROUDART, 2010). Durante o pousio, a floresta rebrota, recuperando a fertilidade do solo, mas varia de região para região, sendo mais rápido nos trópicos e mais lento nas regiões setentrionais frias. Se respeitado o pousio, o sistema é equilibrado ecologicamente, podendo perdurar por milhares de anos. Ainda é usado no mundo (MAZOYER; ROUDART, 2010).

Por séculos a maior parte da produção agrícola voltada para o mercado interno no Brasil foi realizada com esse método, porém de modo incompleto. A abundância de terras permitia executá-lo dentro de uma mesma posse ou propriedade, mas com um tempo de pousio inferior ao

5 Pelo Tratado de Tordesilhas apenas uma pequena parte do que é hoje o Brasil pertencia a Portugal. 
necessário para a recuperação do solo. Com o rápido desenvolvimento urbano-industrial, a partir dos anos 1960 (FURTADO, 1980), há uma mudança nesse quadro. A necessidade em aumentar os excedentes agrícolas para abastecimento urbano foi realizada com base em maior mecanização e uso de insumos (BUAINAIN et al., 2014). A ampliação da produção de grãos, sobretudo, teve impactos importantes nos solos das principais regiões produtoras, causando processos erosivos. Cultivos sem curva de nível, associados ao método de preparo do solo que reproduzia, a exemplo do que era feito na Europa e nos EUA (MAZOYER; ROUDART, 2010), com grande exposição do solo pulverizado por arações e gradagens ao sol e às fortes chuvas tropicais, causaram elevadas taxas de erosão.

Nos anos 1970, pesquisas do Instituto Agronômico de Campinas (IAC) concluíram que, no caso brasileiro, as perdas de solo ultrapassavam $25 \mathrm{t} / \mathrm{ha} /$ ano. Medições efetivadas pela equipe do Projeto Noroeste do Paraná, na área do projeto piloto da Bacia do Ribeirão do Rato, mostraram níveis de perda de solo entre 25 t/ha/ano até 187 t/ha/ano (ROMEIRO; ABRANTES, 1981). A dramaticidade dessa situação se revela na medida em que, em um dos principais estados produtores, o Paraná, a perda de solos atingiu cerca de $1 \mathrm{~cm}$ por ano (ROMEIRO; ABRANTES, 1981). A situação era tão grave que o coordenador do Programa Integrado de Conservação de Solos (PROICS) ${ }^{6}$ do Paraná propunha, como meta aceitável, reduzir as perdas para $25 \mathrm{t} / \mathrm{ha} / \mathrm{ano}$. Em termos internacionais, segundo publicações do Soil Survey Staff e Soil Conservation Service ${ }^{7}$, as perdas máximas admissíveis situavam-se entre 3 e 12 t/ha/ano (ROMEIRO; ABRANTES, 1981).

Essas taxas de erosão, em pouco tempo, destruíram solos mais suscetíveis, como os solos areníticos do oeste paulista e nordeste (norte velho) paranaense (Arenito Caiuá) (ROMEIRO; ABRANTES, 1981). Já os solos profundos de alta qualidade (solos basálticos, conhecidos como terra roxa) resistiram melhor, mas foi necessário o uso crescente de fertilizantes químicos para manter rendimentos não muito elevados. Parte dos fertilizantes era perdida, carreada pelas águas das chuvas, poluindo rios e lagoas, de modo que o efeito sobre o rendimento das culturas foi baixo (ROMEIRO; ABRANTES, 1981).

Esse fato pode ser constatado pelo desempenho da produtividade das sete principais culturas comerciais (algodão, arroz, cana-de-açúcar, café, milho, soja e trigo), que se caracterizavam naquele momento como as mais modernizadas (ROMEIRO; ABRANTES, 1981). Essas culturas respondiam por mais de $75 \%$ do consumo de fertilizantes. Apesar do aumento no uso de fertilizantes, a produtividade aumenta pouco (IBGE, 2020; ROMEIRO; ABRANTES, 1981):

- No algodão observa-se estagnação da produtividade de 1960 a 1970, quando registra aumento da produtividade, atingindo rendimento médio por hectare (média móvel trienal) 57\% maior que em 1977 em relação a 1960.

- A produtividade do arroz apresenta tendência declinante, chegando a 1977 com rendimento médio por hectare $12 \%$ menor que em 1960 .

- A produtividade da cana-de-açúcar evolui lentamente, atingindo em 1977 rendimento médio 22,6\% maior do que em 1960.

\footnotetext{
${ }^{6}$ http://www.prosolo.pr.gov.br

7 https://websoilsurvey.sc.egov.usda.gov/App/HomePage.htm
} 
- No caso do café, a produtividade varia enormemente, mas, na maior parte do tempo, apresenta-se abaixo do rendimento por hectare, chegando a 1977 com rendimento médio 4,7\% menor que em 1960.

- A produtividade do milho evolui lentamente, tendo queda em 1977, quando atingiu rendimento de apenas 14,9\% maior do que em 1960.

- A soja tem produtividade estagnada até 1970 em níveis inferiores aos de 1960, se recuperando para alcançar, em 1977, rendimento médio $29,1 \%$ maior.

- O trigo teve o melhor desempenho, a produtividade cresceu até atingir um máximo em 1970, para cair em seguida e fixar-se, em 1977, a um rendimento médio de 50,8\% superior a 1960 .

Esse fraco desempenho, que já é significativo em si, torna-se dramático quando comparado com os dados relativos à evolução do consumo de fertilizantes químicos (IBGE, 2020; ROMEIRO; ABRANTES, 1981). Embora muitos sejam os fatores responsáveis pelo incremento da produtividade agrícola, e a influência de cada um seja difícil de ser medida e não possa ser isolada da dos demais, normalmente, "aos fertilizantes, dentre os insumos, caberia o principal papel, pois o seu uso per si deveria responder por um incremento de produtividade de $30 \%$ a $40 \%$ em cada cultura, em solos de baixa produtividade" (AGROANALYSIS, 1980).

O consumo de fertilizantes por hectare cresceu 954\% entre 1960 e 1977; descontada a expansão da área cultivada, cerca de 71\%, tem-se expansão de 513\% (AGROANALYSIS, 1980). Ou seja, o incremento de cinco vezes no uso de fertilizantes por hectare não resultou em aumento significativo de produtividade, como era de se esperar. Seu efeito foi manter os rendimentos em um quadro de forte erosão dos solos.

Outro problema ambiental e socioeconômico causado pelas modernas práticas agrícolas é a poluição química decorrente do uso de pesticidas. Em trabalho notório na época, Paschoal (1979), professor da Escola Superior de Agricultura Luiz de Queiroz (Esalq/USP), mostrou que havia correlação entre a intensificação do uso de pesticidas com o aumento do número de pestes. O consumo de agrotóxicos cresce exponencialmente, a partir de 1964, até atingir um pico em 1974 com consumo 518\% superior, caindo para se fixar, em 1977, em um nível 383\% acima do ano-base; se descontada a expansão da área colhida, obter-se-ia um índice "líquido" de consumo de agrotóxicos, refletindo a intensificação de sua utilização, que mostra aumento em seu consumo por hectare de 379\% entre 1964 e 1974, baixando, em 1977, para 220\%. A provável explicação está nas especificidades do clima tropical, por conta da dinâmica reprodutiva dos insetos e outros agentes patogênicos, devido à ausência de uma estação fria (com neve), que reduz o nível de atividade biológica (ROMEIRO, 1998).

O problema da erosão no Brasil somente será equacionado com a adoção de práticas de conservação de solo, em especial com a expansão do sistema de plantio direto (ALVARES et al., 1995; FEDERAÇÃO BRASILEIRA DE PLANTIO DIRETO NA PALHA; CONAB, 2012; IBGE, 2020; ZIMMER et al., 2012). Entretanto, no caso da poluição química por pesticidas, esta continuará a ser um grave problema, embora a eficácia do plantio direto tenha aumentado 
de modo a permitir que as melhorias na genética das cultivares e na conservação da fertilidade do solo se expressassem em significativos aumentos de rendimento das culturas (IBGE, 2020).

A inovação foi um fator decisivo nessa trajetória (GASQUES et al., 2019; VIEIRA FILHO; GASQUES, 2016). Mas o modelo tecnológico beneficiou principalmente os grandes produtores de grãos voltados para exportação de cana-de-açúcar, e em função do Proálcool, ameaçando a permanência de milhões de produtores na atividade (ALVES et al., 2012; BUAINAIN; GARCIA, 2013a, 2013b). A área dedicada à soja passou de 10 milhões de hectares para mais de 30 milhões, revelando o padrão agrícola baseado na ocupação de novas áreas produtivas. Enquanto isso, a área ocupada por produtos tradicionais dos brasileiros, tais como o arroz, o feijão, a mandioca e o trigo, foi reduzida pela metade; embora a produção tenha aumentado, mais uma evidência dos ganhos de produtividade na agropecuária (IBGE, 2020), produtividade impulsionada pelo uso de agroquímicos.

Em 2014, os produtores usaram mais de 14 milhões de toneladas de fertilizantes (IBGE, 2020). Com isso, o consumo saltou de $69 \mathrm{~kg} / \mathrm{ha}$, em 1992, para $184 \mathrm{~kg} / \mathrm{ha}$ em 2014, aumento de $165 \%$. O consumo de ingredientes ativos por área plantada saltou de 3,2 kg/ha, em 2000, para $6,7 \mathrm{~kg} / \mathrm{ha}$ em 2014 (IBGE, 2020), crescimento de 109\% (FAO, 2019). Por um lado, esse aumento também seria resultado da realização de mais uma safra na mesma área. Por outro, as áreas são usadas com maior intensidade e sofrem com o maior uso de agroquímicos. Por fim, intensificação do uso de agroquímicos também foi associada à introdução de cultivares com maior potencial genético, bem como a práticas de controle de erosão.

Esse cenário revela que, apesar do desempenho da agricultura brasileira, verificado desde os anos 1970, a sustentabilidade ambiental e a socioeconômica dependeram e continuam a depender do enfrentamento de alguns desafios, dentre eles o equacionamento dos problemas ambientais e sociais.

\section{É possível uma agricultura de base ecológica no Brasil?}

A erosão do solo foi historicamente o principal problema causado pela agricultura em regiões tropicais (HARTEMINK, 2005; RATES et al., 2016). No Brasil, como visto acima, esse problema atingiu níveis alarmantes. A abundância de terras foi um fator responsável pela negligência durante muito tempo (ROMEIRO, 1998). Por um lado, os solos profundos e bem-estruturados, nos quais se iniciou a modernização agrícola, tiveram o efeito paradoxal de retardar as ações contra erosão, na medida em que não afetavam a produtividade. Por outro, os subsídios ao crédito agrícola nos anos 1970 (SANTANA et al., 2014) também contribuíram para retardar as ações contra a erosão, na medida em que a intensificação do uso de fertilizantes subsidiados mascarou o efeito da erosão sobre os rendimentos. Mas o fim dos subsídios nos anos 1980, em razão da crise econômica (SANTANA et al., 2014), foi um fator para a adoção de práticas conservacionistas de solo pelos agricultores, ainda mais preocupados com o prejuízo econômico imediato do que com a conservação dos solos no longo prazo.

No estado do Paraná teve início, nos anos 1980, um bem-sucedido programa estadual de conservação de solos em microbacias, estendido para outros estados e depois se convertendo no Programa Nacional de Microbacias Hidrográficas e Conservação de Solo na Agricultura 
(BRASIL, 2016b). As principais ações foram o controle mecânico do escorrimento superficial da água, como curvas de nível e terraceamento. Um grande obstáculo era a forma como se deu a apropriação da terra no Paraná, com os lotes se constituindo de longas faixas estreitas em declive, partindo do divisor de águas até a beira dos cursos d'água (ROMEIRO, 1998). Além das práticas de conservação, cabe destacar o avanço do plantio direto ${ }^{8}$ (FEDERAÇÃO BRASILEIRA DE PLANTIO DIRETO NA PALHA; CONAB, 2012).

O sistema de plantio direto é baseado em princípios agroecológicos de gestão de SEs: os restos de cultura, após a colheita, são triturados e incorporados superficialmente ao solo, configurando um colchão de proteção contra o sol e a energia cinética das chuvas e fornecendo matéria orgânica à microvida do solo (CASSOL et al., 2007). As condições de preparo do solo para a implantação direta das sementes são obtidas como resultado das atividades metabólicas da microvida do solo. Estima-se que mais de 30 milhões de hectares sejam cultivados com o sistema de plantio direto no Brasil (FEDERAÇÃO BRASILEIRA DE PLANTIO DIRETO NA PALHA; CONAB, 2012; IBGE, 2020).

Outra importante inovação baseada em SEs foi a fixação biológica de nitrogênio (FBN) (DÖBEREINER, 1997; EMBRAPA, 2014). O nitrogênio (N) é um dos nutrientes que mais limitam o crescimento das plantas, sobretudo em regiões tropicais. Assim, fixação biológica ocorre a partir da simbiose de bactérias fixadoras de $\mathrm{N}$ (azotobacter) com raízes de plantas leguminosas. Tem a vantagem de eliminar as perdas de $\mathrm{N}$ que ocorrem com a fertilização nitrogenada comercial (EMBRAPA, 2014). A inovação consistiu no desenvolvimento de inoculantes com bactérias fixadoras que potencializam a fixação natural do nitrogênio.

Estima-se que a fixação biológica de nitrogênio tenha sido adotada em 34 milhões de hectares cultivados com soja na safra 2016/2017 (EMBRAPA, 2018). Essa inovação não apenas permitiu que o Brasil poupasse bilhões de dólares com a compra de fertilizantes nitrogenados, como também reduziu a poluição derivada das perdas de N, como eutrofização de cursos d'água, poluição de lençóis freáticos com nitratos e emissão de gases de efeito estufa. O uso de $1 \mathrm{~kg}$ de fertilizante nitrogenado emite o equivalente a $10 \mathrm{~kg}$ de $\mathrm{CO}_{2}$ (DÖBEREINER, 1997). A emissão anual de $\mathrm{CO}_{2}$ evitada foi estimada em mais de 2 milhões de toneladas de $\mathrm{CO}_{2}$ equivalente, na safra 2016/2017, apenas no cultivo de soja, redução acumulada entre 2010 e 2017 de mais de 30 milhões de toneladas (EMBRAPA, 2018).

O mesmo não ocorreu com outra grande fonte de poluição química na agricultura: o uso de pesticidas. O Brasil é importante consumidor mundial de pesticidas, e as denúncias de problemas causados por eles se multiplicam, incluindo o uso de substâncias há muito proibidas em outros países (CARNEIRO et al., 2015). Esforços foram feitos para reduzir a utilização, por meio de manejo integrado de pragas, em que o pesticida é usado em doses menores (CORREA-FERREIRA et al., 2010; SEDIYAMA, 2009). Mas a maior complexidade de manejo parece ter sido o principal fator da limitação de sua difusão. O sucesso do controle da lagarta que ataca a soja foi rea-

\footnotetext{
O sistema de plantio direto foi desenvolvido nos EUA (no-tillage) nos anos 1940 (KASSAM et al., 2014). No Brasil, os primeiros esforços para adaptação em regiões tropicais tiveram início nos anos 1970, no Paraná, por iniciativa de um agricultor da região de Guarapuava, Herbert Bartz, onde os solos eram rasos e suscetíveis à erosão (CASSOL et al., 2007). Os esforços atraíram a atenção de pesquisadores do Instituto Agronômico do Paraná (Iapar) e, depois, da Empresa Brasileira de Pesquisa Agropecuária (Embrapa). Mais de 20 anos foram necessários para que os ajustes fossem feitos e a prática começasse a se difundir de modo amplo pelo Brasil.
} 
lizado com um vírus que pode ser produzido pelo produtor a partir do maceramento de lagartas contaminadas e depois pulverizadas nas lavouras (BARBOSA et al., 2013). Apesar de o problema com o uso excessivo de pesticidas ainda não estar equacionado (CARNEIRO et al., 2015), houve avanços na promoção de práticas agrícolas com base agroecológica no Brasil (ROMEIRO, 2014). Além de essa ter passado a ser uma orientação geral da pesquisa da Embrapa foram criadas unidades de pesquisa dedicadas a esse tema: Agrobiologia e Meio Ambiente (EMBRAPA, 2020).

Outros problemas ambientais que surgem da intensificação e do aumento da escala de produção é a escassez de recursos hídricos para abastecer os sistemas irrigados, além da geração de resíduos agropecuários e agroindustriais - dejetos de aves e suínos e vinhaça da produção de álcool e açúcar. $\mathrm{O}$ avanço dos sistemas irrigados contribuiu para o aumento no uso de insumos e dos recursos naturais. Segundo dados do Atlas da Irrigação no Brasil (AGÊNCIA NACIONAL DE ÁGUAS E SANEAMENTO BÁSICO, 2017), os sistemas irrigados ocupam entre 4 e 7 milhões de hectares concentrados na produção de arroz (1,5 milhão de hectares) e cana-de-açúcar (3,5 milhões de hectares), em termos espaciais, no Sul (25\%) e Sudeste (40\%), mas em forte expansão no Centro-Oeste e Nordeste. Essa dinâmica, incentivada pelo Estado, está gerando uma enorme pressão sobre os recursos hídricos. A demanda hídrica foi estimada em $969 \mathrm{~m} / \mathrm{segundo}$ (AGÊNCIA NACIONAL DE ÁGUAS E SANEAMENTO BÁSICO, 2017).

Além do desmatamento, a intensificação da agricultura, que permite até três safras por ano (IBGE, 2020), e o aumento da escala de produção alteraram a sua relação com o meio ambiente no Brasil. A modernização da agricultura potencializou disfunções que se manifestam com intensidade diferenciada entre as regiões produtoras: escassez de recursos hídricos; problema da destinação dos resíduos; contaminação química; perda da biodiversidade e mudanças climáticas "locais", com alteração nos períodos de chuvas e elevação da temperatura.

Diante de tal cenário e de maior consciência social dos impactos ambientais da moderna agricultura, induziu-se esforço de normatização e definição de políticas. Nesse contexto, merecem destaque a Política Nacional de Mudanças Climáticas (Lei n ${ }^{\circ} 12.187 / 2009$ ) e o Código Florestal (Lei $\mathrm{n}^{0}$ 12.651/2012). A primeira ratifica os compromissos assumidos pelo País nas Convenções-Quadro das Nações Unidas (ONU) de mudanças climáticas. Como o desmatamento é um importante problema a ser enfrentado, porque afeta a imagem internacional da agricultura brasileira, o Novo Código Florestal ganha destaque.

Cabe destacar as ações para reduzir o desmatamento, como o Programa de Cálculo do Desmatamento na Amazônia (Prodes), executado pelo Instituto Nacional de Pesquisas Espaciais (Inpe); Plano de Ação para a Prevenção e Controle do Desmatamento na Amazônia Legal (PPCDAM); Plano de Ação para Prevenção e Controle do Desmatamento e das Queimadas no Cerrado (PPCERRADO). No entanto, as metas de redução das taxas anuais de desmatamento são de 10 mil km² para o Cerrado e de 4 mil km² para a Amazônia (BRASIL, 2016a).

Em 2014, a área desmatada na Amazônia Legal alcançou 4,4 mil km², uma das menores na série histórica. Já houve registro de 27,8 mil km² em 2004, mas em 2019 alcançou 10,3 mil km³ (INPE, 2020). No Cerrado, o berço da moderna agricultura, em 2004, o desmatamento alcançou 30 mil km², maior taxa da série histórica; em 2019 foi de 6,5 mil km² (INPE, 2020). A redução nas 
taxas anuais de desmatamento da Amazônia e Cerrado, embora importante e próxima das metas, ainda é elevada devido ao grau de degradação e importância dos biomas.

O desmatamento ainda prossegue, mesmo em biomas com elevado grau de degradação, como é o caso da Mata Atlântica. Portanto, o País está distante do "desmatamento ilegal zero" (FUNDAÇÃO SOS PRO-MATA ATLÂNTICA, 2020; INPE, 2020). Na tentativa de reverter esse quadro, em razão de sua forte relação com a agricultura, dos compromissos de redução das emissões de gases de efeito estufa, dos prejuízos econômicos decorrentes dos problemas ambientais, da pressão da sociedade civil e dos principais mercados agrícolas importadores, e para o desenvolvimento de uma agricultura sustentável, uma importante ação foi a criação do Programa Agricultura de Baixo Carbono (ABC) em 2010 (Decreto no 7.390/2010), cujo objetivo é dar uma resposta da agricultura ao desafio da mudança climática (AGRICULTURA..., 2013; BRASIL, 2018b).

Uma das metas do Programa ABC é reduzir as emissões em 10 milhões de toneladas de $\mathrm{CO}_{2}$ equivalente até 2020 (BRASIL, 2018a). Para tanto, a aplicação de princípios agroecológicos se impõe nos sistemas agropecuários. As ações devem ir além das práticas já mencionadas, como o plantio direto e a fixação biológica de N, devem estimular o desenvolvimento de sistemas produtivos alternativos, tais como a Integração Lavoura-Pecuária (iLP), Lavoura-Pecuária-Floresta (iLPF) e sistemas agroflorestais (SAFs) (ALVES et al., 2015; PARRON et al., 2019).

Os resultados mostram que, entre 2010 e janeiro/2019, foram 34.271 contratos; $R \$ 17,3$ bilhões desembolsados de R \$ 27,7 bilhões disponibilizados (BRASIL, 2020a); entre 2010 e 2018 estimou-se uma expansão de 4,46 milhões de hectares de recuperação de pastagens degradadas (a meta era 10 milhões), contribuindo para o sequestro de 16,9 a 57,5 milhões de $\mathrm{MgCO}_{2}$ eq. (corresponde ao cumprimento da meta de 18\% a 62\%) (BRASIL, 2020a). No caso do iLPF, os dados mostram uma expansão de 5,8 milhões de hectares entre 2010 e 2016, superando a meta, contribuindo para o sequestro de 22,1 milhões de $\mathrm{MgCO}_{2}$ eq. Por fim, no caso do plantio direto, os resultados mostram uma expansão de 9,9 milhões de hectares entre 2010 e 2016, superando a meta, sequestro estimado de 18,3 milhões de $\mathrm{MgCO}_{2}$ eq. (BRASIL, 2020a) 9 .

Além de contribuir para a redução das emissões de gases de efeito estufa, esses sistemas de produção oferecem um enorme potencial de recuperação de áreas degradadas (ZIMMER et al., 2012). Estima-se que o Brasil possua 100 milhões de hectares com pastagens degradadas (DIASFILHO, 2014, 2016), área maior que a utilizada para a produção agrícola (IBGE, 2020). Segundo Dias-Filho (2016), a pecuária bovina em pastagens naturais tem sido praticada sem qualquer manejo (stricto sensu) no Brasil; mesmo nas pastagens plantadas, a atividade tem sido desenvolvida com baixo investimento em insumos e tecnologia.

Um agravante é que "as pastagens naturais brasileiras normalmente carecem de espécies com melhor aptidão forrageira, isto é, com alta adaptação ao pastejo [...] e com produtividade e valor nutritivo relativamente mais elevados. Ademais, [...] grande parte das áreas de pastagens naturais no Brasil" estão em "locais com solos mais pobres em nutrientes" (DIAS-FILHO, 2016, p. 25). A recuperação das pastagens degradadas pode ter um importante papel na redução da pressão da fronteira agrícola sobre a Amazônia e o Cerrado.

$\overline{9}$ Os resultados para as demais ações estão disponíveis em Brasil (2020a). 
Apesar de o País dispor de um completo e complexo aparato institucional (BREDARIOL; VINHA, 2015), a sua aplicação está distante da teoria. Um importante fator institucional de grande impacto ecológico, específico do cenário brasileiro, é o Novo Código Florestal (Lei $n^{\circ}$ 12.651/2012) (BRASIL, 2012a). Um avanço foi a criação do Cadastro Ambiental Rural (CAR) ${ }^{10}$, artigo 29 do Código Florestal, cujo objetivo é promover a integração das informações dos estabelecimentos rurais quanto às áreas de preservação permanente (APPs), uso restrito, reserva legal, remanescentes florestais nativos e das áreas consolidadas (BRASIL, 2012a).

O Código Florestal veio consolidar e ampliar um quadro existente no País, que é a relação da agropecuária com remanescentes florestais nativos. O Código Florestal obriga os agricultores a preservarem áreas de vegetação natural permanente ao longo dos cursos d'água e em áreas a partir de certo grau de inclinação e topo de morro; a manterem de 20\% a 80\% da área da propriedade rural na forma de uma reserva legal. Independentemente da legislação, parte dos estabelecimentos rurais vinha mantendo remanescentes florestais nativos, conforme revelado pelo Censo Agropecuário de 2017 (IBGE, 2020). Essa característica tem sido reforçada com a publicação dos dados preliminares do Cadastro Ambiental Rural (CAR) (BRASIL, 2020c).

Nas áreas com remanescentes florestais nativos, a agropecuária, se manejada com base em princípios agroecológicos, pode oferecer importantes SEs dentro e fora da propriedade (ZHANG et al., 2007), tais como ciclagem de nutrientes, fertilidade do solo, controle de erosão, de pragas e doenças, polinização, controle de cheias e inundações, purificação e provisão de água. Há ainda o serviço de biodiversidade que beneficia toda a sociedade, mas que representa um ônus aos agricultores.

Apesar do avanço na adoção de práticas agroecológicas pelos produtores rurais no País, os resultados ainda estão distantes de uma agricultura sustentável. O desmatamento está distante de ser equacionado, e, a partir dos anos 2019, há sinais de aumento das suas taxas (INPE, 2020) em razão das mudanças na política ambiental brasileira (FEARNSIDE, 2019; GARCIA, 2019; SCANTIMBURGO, 2018; TRIGUEIRO, 2019). Desde 2009, as taxas de desmatamento na Amazônia Legal indicavam uma tendência de redução e estabilização entre 4 e 6 mil km²/ano; mas, a partir de 2015, há uma reversão, em que o novo patamar estaria em 7 mil km²/ano; em 2019 alcançou 10,3 mil km³ (INPE, 2020). O Cerrado, embora registre taxas próximas a 7 mil $\mathrm{km}^{2} /$ ano desde 2016, ainda não mostra sinais de redução em função do alto grau de degradação, por volta de $50 \%$ de sua área original foi desmatada (INPE, 2020).

Outra questão importante é o aumento no registro e na liberação de agrotóxicos, alcançando 475 novos registros apenas em 2019, em que $28 \%$ são qualificados como extremamente tóxicos (BRASIL, 2020b). A aceleração tem seu início em 2016, quando verificou-se aumento de 99\%, saltando de 139 registros em 2015 para 277 em 2016; 405 em 2017; 449 em 2018 (BRASIL, 2020b). Essa tendência é preocupante, mas deve ser analisada com cautela, em função da obsolescência dos agrotóxicos. Isso porque os agrotóxicos não apenas contaminam o meio ambiente, mas também ameaçam a saúde humana, além de fecharem as portas para o mercado internacional, para a agricultura brasileira, a partir das barreiras não tarifárias.

\footnotetext{
${ }^{10}$ Esse cadastro corresponde a um registro georreferenciado das informações quanto ao perímetro do imóvel rural, áreas de interesse social, utilidade pública e ambientais. Para auxiliar na sua execução foi criado o Sistema Nacional de Cadastro Ambiental Rural, o Sicar (BRASIL, 2012b).
} 
Um aspecto interessante na drástica reversão da agenda ambiental brasileira é o apoio de parcela dos produtores rurais (FEARNSIDE, 2019). Ainda, o modelo de desenvolvimento da agropecuária seguido até então parece apresentar sinais de esgotamento, com redução no ritmo dos ganhos de produtividade (GASQUES et al., 2016) e no avanço dos problemas sociais e ambientais (ALVES; ROCHA, 2010; BUAINAIN; GARCIA, 2013a, 2013b; CARNEIRO et al., 2015). Desse modo, o desenvolvimento de novas tecnologias pautadas no uso e na gestão dos recursos naturais - abordagem baseada em SE - vem atender a uma demanda crescente da sociedade e à forte pressão da problemática ambiental e das mudanças climáticas. A adoção de princípios agroecológicos nas práticas agrícolas pode levar a um novo paradigma tecnológico e produtivo na agropecuária brasileira (ROMEIRO, 2014). A transição para uma agropecuária baseada em SEs também deve estar ancorada em um comprometimento do governo brasileiro a partir do avanço institucional e de sua aplicação, que parece distante da realidade.

\section{Conclusões}

O desenvolvimento da agropecuária é uma importante estratégia da sociedade para ampliar os benefícios já providos pelos ecossistemas, os SEs de provisão de alimentos, fibras e energia. Isso porque a expansão natural do SE de provisão depende do número de plantas ou das condições ambientais favoráveis, as quais são lentas e incertas. Mas a realização do plantio planejado de determinadas espécies já domesticadas representa uma estratégia mais certa para garantir a expansão, por exemplo, da produção de alimentos. Essa ação está alinhada ao objetivo principal da agropecuária, que é garantir a segurança alimentar da sociedade. Essa estratégia tem sido apoiada pelo avanço da tecnologia, e o Brasil tem sido considerado um caso de sucesso, apesar dos custos ambientais e sociais.

Contudo, em função da escala alcançada pela agropecuária ao longo do século XX, inclusive a brasileira, essa estratégia tem afetado sobremaneira o provimento de outros SEs, situação que pode comprometer a sua sustentabilidade. A agropecuária tem posto em segundo plano o provimento dos demais SEs em benefício apenas da rentabilidade econômica de curto prazo. O resultado tem sido um avanço dos impactos ambientais e socioeconômicos sobre a própria dinâmica da agropecuária, que até pouco tempo eram contornados de maneira relativa com o avanço da tecnologia. Não é possível negar que a inovação tecnológica tem tido um importante papel no avanço da agropecuária brasileira, mas tampouco é possível ignorar seus impactos ambientais e socioeconômicos.

Essa dinâmica tem apresentado sinais de esgotamento, inclusive com uma desaceleração do ritmo dos ganhos de produtividade. Desse modo, ao mesmo tempo em que a agropecuária brasileira alcança importantes ganhos de produtividade, enfrenta problemas associados às restrições ecológicas, em grande medida resultado do modelo baseado no monocultivo de larga escala e no excessivo dos recursos naturais. Sem perder de vista que o desmatamento não retrocede no Brasil, mesmo em biomas extremamente degradados como a Mata Atlântica. Neste contexto, uma alternativa que está ganhando espaço seria um retorno aos princípios ecológicos básicos que governam a produção agropecuária desde sempre. Isso significa que a adoção de princípios agroecológicos seria o novo paradigma tecnológico na agropecuária para fazer frente aos imensos desafios postos no século XXI, ampliar a produção e, ao mesmo tempo, proteger a provisão de 
importantes SEs. Os novos modelos de sistemas produtivos mais sustentáveis, que vêm sendo desenvolvidos e propostos pela Embrapa, e o relativo sucesso de sua adoção representam uma grande esperança. Porém, ainda persistem desafios enormes para que essa alternativa se torne o novo padrão agropecuário no Brasil. E tanto a crise socioeconômica como a mudança no perfil do governo têm contribuído para desacelerar a transição para uma agropecuária mais sustentável.

\section{Referências}

AGÊNCIA NACIONAL DE ÁGUAS E SANEAMENTO BÁSICO - ANA. Atlas irrigação: uso da água na agricultura irrigada. Brasília, DF, 2017. 85 p. Disponível em: http://www3.ana.gov.br/portal/ANA/ noticias/estudo-da-ana-aponta-em-45-potencial-de-expansao-da-irrigacao-no-brasil-ate-2030/ana_atlasirrigacao-usodaaguanaagriculturairrigada.pdf/view. Acesso em: 26 jun. 2021.

AGRICULTURA de baixa emissão de carbono: a evolução de um novo paradigma: relatório completo. São Paulo: Fundação Getúlio Vargas, [2013]. Projeto Observatório ABC. Coordenador do estudo: Eduardo Delgado Assad.

AGROANALYSIS. Agroanalysis - Grupo de Informação Agrícola. Rio de Janeiro: Fundação Getúlio Vargas, 1980. Disponível em: http://bibliotecadigital.fgv.br/ojs/index.php/agroanalysis/issue/archive. Acesso em: 26 jun. 2021.

ALVARES, V. H. V.; FONTES, L. E. F.; FONTES, M. P. F. O solo nos grandes domínios morfoclimáticos do Brasil e o desenvolvimento sustentando. In: CONGRESSO BRASILEIRO DE CIÊNCIA DO SOLO, 25., 1995, Viçosa, MG. O solo nos grandes domínios morfoclimáticos do Brasil e o desenvolvimento sustentado: resumos expandidos. Viçosa, MG: Sociedade Brasileira de Ciência do Solo: Universidade Federal de Viçosa, 1995.

ALVES, E.; ROCHA, D. P. Ganhar tempo é possível? In: GASQUES, J. G.; VIEIRA-FILHO, J. E.; NAVARRO, Z. (Ed.). A agricultura brasileira: desempenho, desafios e perspectivas. Brasília, DF: IPEA, 2010. p. 275-290.

ALVES, E.; SOUZA, G. da S. E.; ROCHA, D. de P. Lucratividade da agricultura. Revista de Política Agrícola, v. 21, n. 2, p. 45-63, 2012.

ALVES, F. V.; LAURA, V. A.; ALMEIDA, R. G. de. Sistemas agroflorestais: a agropecuária sustentável. Brasília, DF: Embrapa, 2015. 208 p.

ASSIS, R. L.; ROMEIRO, A. R. Agroecologia e agricultura orgânica: controvérsias e tendências. Desenvolvimento e Meio Ambiente, n. 6, p. 67-80, 2002.

BALSAN, R. Impactos decorrentes da modernização da agricultura brasileira. Campo - Território: Revista De Geografia Agrária, v. 1, n. 2, p. 123-151, 2006.

BARBOSA, G. C. et al. Controle biológico e manejo de pragas na agricultura sustentável. In: JORNADA ACADÊMICA DA EMBRAPA SOJA, 8., 2013, Londrina. Resumos expandidos... Londrina: Embrapa Soja, 2013. (Embrapa Soja. Documentos, 339).

BITTENCOURT, M. V. L. Impactos da agricultura no meio-ambiente: principais tendências e desafios (Parte 1). Revista Economia \& Tecnologia, 2009.

BITTENCOURT, M. V. L. Impactos da agricultura no meio ambiente: principais tendências e desafios (Parte 2). Revista Economia \& Tecnologia, 2010. 
BRANDENBURG, A.; LAMINE, C.; DAROLT, M. Institucionalização do movimento ecológico na agricultura: mercado e reorganização dos atores sociais. Estudos Sociedade e Agricultura, v. 21, n. 2, p. 221-247, 2013.

BRASIL. Lei no 12.651, de 25 de maio de 2012. Dispõe sobre a proteção da vegetação nativa. Brasília, DF, 2012a. Disponível em: http://www.planalto.gov.br/ccivil_03/_ato2011-2014/2012/lei/L12651compilado. htm. Acesso em: 1 mar. 2018.

BRASIL. Decreto no 7.830, de 17 de outubro de 2012. Dispõe sobre o Sistema de Cadastro Ambiental Rural, o Cadastro Ambiental Rural, estabelece normas de caráter geral aos Programas de Regularização Ambiental, de que trata a Lei $\mathrm{n}^{\circ} 12.651$, de 25 de maio de 2012, e dá outras providências. Brasília, DF, 2012b. Disponível em: http://www.planalto.gov.br/ccivil_03/_ato2011-2014/2012/decreto/D7830.htm. Acesso em: 1 mar. 2018.

BRASIL. Ministério da Agricultura, Pecuária e Abastecimento. Informações técnicas. Disponível em: http://www.agricultura.gov.br/assuntos/insumos-agropecuarios/insumos-agricolas/agrotoxicos/informacoes-tecnicas. Acesso em: 18 mar. 2020a.

BRASIL. Ministério da Agricultura, Pecuária e Abastecimento. Programas e orientações. Disponível em: http://www.agricultura.gov.br/assuntos/sustentabilidade/plano-abc/programas-e-orientacoes. Acesso em: 14 mar. 2018 a.

BRASIL. Ministério da Agricultura, Pecuária e Abastecimento. Plano ABC - agricultura de baixa emissão de carbono. Disponível em: http://www.agricultura.gov.br/assuntos/sustentabilidade/plano-abc. Acesso em: 14 mar. 2018b.

BRASIL. Ministério da Agricultura, Pecuária e Abastecimento. Plano ABC em números. Disponível em: http://www.agricultura.gov.br/assuntos/sustentabilidade/plano-abc/plano-abc-em-numeros. Acesso em: 11 mar. 2020b.

BRASIL. Ministério da Agricultura, Pecuária e Abastecimento. Sicar - Sistema de Cadastro Ambiental Rural. Disponível em: http://www.car.gov.br/\#/. Acesso em: 1 mar. 2020c.

BRASIL. Ministério do Meio Ambiente. Planos de ação para a prevenção e o controle do desmatamento - documento base: contexto e análises (versão preliminar). Brasília, DF: [2016a]. Disponível em: https://www.gov.br/mma/pt-br/assuntos/servicosambientais/controle-de-desmatamento-e-incendios-florestais/pdf/Documentobasecontextoeanlisededados.pdf. Acesso em: 26 jun. 2020.

BRASIL. Ministério da Agricultura, Pecuária e Abastecimento. Programas e orientações. 2016 b. Disponível em: https://www.gov.br/agricultura/pt-br/assuntos/sustentabilidade/plano-abc/programas-e-orientacoes. Acesso em: 26 jun. 2021.

BREDARIOL, T. de O.; VINHA, V. G. da. Instituições e governança ambiental: uma revisão teórica. Revista Iberoamericana de Economia Ecológica, v. 24, n. 1, p. 153-162, 2015.

BUAINAIN, A. M. et al. (Ed.). O mundo rural no Brasil do século 21: a formação de um novo padrão agrário e agrícola. Brasília, DF: Embrapa, 2014. 1182 p.

BUAINAIN, A. M.; GARCIA, J. R. Contextos locais ou regionais: importância para a viabilidade econômica dos pequenos produtores. In: NAVARRO, S. K. C. Z. (Ed.). A pequena produção rural e as tendências do desenvolvimento agrário brasileiro: ganhar tempo é possível? Brasília, DF: Centro de Gestão e Estudos Estratégicos - CGEE, 2013a. p. 133-176. 
BUAINAIN, A. M.; GARCIA, J. R. Os pequenos produtores rurais mais pobres ainda tem alguma chance como agricultores? In: NAVARRO, S. K. C. Z. (Ed.). A pequena produção rural e as tendências do desenvolvimento agrário brasileiro: ganhar tempo é possível?. Brasília, DF: Centro de Gestão e Estudos Estratégicos - CGEE, 2013b. p. 29-70.

CANO, W. Raízes da concentração industrial em São Paulo. 4. ed. Campinas: Unicamp, 1998.

CARNEIRO, F. F. et al. (Org.). Dossiê ABRASCO: um alerta sobre os impactos dos agrotóxicos na saúde. Rio de Janeiro: Escola Politécnica de Saúde João Venâncio; São Paulo: Expressão Popular, 2015. 623 p.

CASSOL, E. A.; DENARDIN, J. E.; KOCHHANN, R. A. Sistema plantio direto: evolução e implicações sobre a conservação do solo e da água. Viçosa: Sociedade Brasileira de Ciência do Solo, 2007. (Nota técnica).

CORRÊA-FERREIRA, B. S. et al. Práticas de manejo de pragas utilizadas na soja e seu impacto sobre a cultura. Londrina: Embrapa Soja, 2010. 15 p. (Embrapa Soja. Circular Técnica, 78).

DAILY, G. C. Nature's services: societal dependence on natural ecosystems. [Washington, DC]: Island Press, 1997.

DE GROOT, R. S.; WILSON, M. A.; BOUMANS, R. M. J. A typology for the classification, description and valuation of ecosystem functions, goods and services. Ecological Economics, v. 41, n. 3, p. 393-408, 2002.

DIAS-FILHO, M. B. Diagnóstico das pastagens no Brasil. Belém, PA: Embrapa Amazônia Oriental, 2014. 36 p. (Embrapa Amazônia Oriental. Documentos, 402). Disponível em: https://www.infoteca.cnptia.embrapa.br/bitstream/doc/986147/1/DOC402.pdf. Acesso em: 26 jun. 2021.

DIAS-FILHO, M. B. Uso de pastagens para a produção de bovinos de corte no Brasil: passado, presente e futuro. Belém, PA: Embrapa Amazônia Oriental, 2016. 42 p. (Embrapa Amazônia Oriental. Documentos, 418). Disponível em: https://ainfo.cnptia.embrapa.br/digital/bitstream/item/141771/1/ DOCUMENTOS-418.pdf. Acesso em: 26 jun. 2021.

DÖBEREINER, J. A importância da fixação biológica de nitrogênio para a agricultura sustentável. Biotecnologia Ciência, 1997.

DOMINATI, E.; PATTERSON, M.; MACKAY, A. A framework for classifying and quantifying the natural capital and ecosystem services of soils. Ecological Economics, v. 69, n. 9, p. 1858-1868, 15 jul. 2010.

EMBRAPA. Balanço social 2017. Brasília, DF: 2018. Disponível em: http://bs.sede.embrapa.br/2017/ balsoc17.html. Acesso em: 26 jun. 2021.

EMBRAPA. Fixação biológica de nitrogênio. [s.1.], 2014.

EMBRAPA. Unidades - Embrapa no Brasil. Portal Embrapa. Disponível em: https://www.embrapa.br/ embrapa-no-brasil. Acesso em: 18 mar. 2020.

FAO. FAOSTAT: Food and agriculture data. Disponível em: http://www.fao.org/faostat/en/\#home. Acesso em: 25 ago. 2019.

FEARNSIDE, P. M. O desmonte da legislação ambiental. In: WEISS, J. S. (Ed.). Movimentos socioambientais: lutas, avanços, conquistas, retrocessos e esperanças. Xapori: Formosa, 2019. p. 317-382.

FEDERAÇÃO BRASILEIRA DE PLANTIO DIRETO NA PALHA; CONAB. Evolução da área cultivada no sistema de plantio direto na palha - Brasil. Foz do Iguaçu, 2012. Disponível em: http://www. febrapdp.org.br/download/PD_Brasil_2013.pdf. Acesso em: 14 mar. 2018. 
FUNDAÇÃO SOS PRO-MATA ATLÂNTICA. Atlas da Mata Atlântica. Disponível em: https://www. sosma.org.br/iniciativa/atlas-da-mata-atlantica/. Acesso em: 5 set. 2020.

FURTADO, C. Formação econômica do Brasil. 17. ed. São Paulo: Editora Nacional, 1980.

GARCIA, G. Vinte e um fatos que comprovam o desmonte da política ambiental. Portal Uol. Congresso em Foco, 20 ago. 2019.

GASQUES, J. G. et al. Nota: produtividade da agricultura brasileira - algumas atualizações. Brasília, DF: MAPA, 2019. Disponível em: https://www.gov.br/agricultura/pt-br/assuntos/noticias/produtividade-da-agropecuaria-cresce-3-43-ao-ano. Acesso em: 26 jun. 2021.

GASQUES, J. G. et al. Produtividade da agricultura brasileira: hipótese da desaceleração. In: VIEIRA FILHO, J. E. R.; GASQUES, J. G. (Ed.). Agricultura, transformação produtiva e sustentabilidade. Brasília, DF: IPEA, 2016. p. 143-163.

GIULIANI, G. M. Profissionalização dos produtores rurais e a questão ambiental. Estudos Sociedade e Agricultura, v. 5, n. 2, p. 102-126, 1997.

GONÇALVES, S. L.et al. Rotação de culturas. Londrina: Embrapa Soja, 2007.9p. (Embrapa Soja. Circular técnica, 45). Disponível em: https://ainfo.cnptia.embrapa.br/digital/bitstream/CNPSO-2009-09/27612/1/ circtec45.pdf. Acesso em: 26 jun. 2021.

HARTEMINK, A. E. Plantation agriculture in the tropics: environmental issues. Outlook on Agriculture, v. 34, n. 1, p. 11-21, 2005.

IBGE. Sistema IBGE de Recuperação Automática - SIDRA. Disponível em: https://sidra.ibge.gov.br/. Acesso em: 22 abr. 2020.

INPE. TerraBrasilis - PRODES: Programa de Monitoramento da Floresta Amazônica Brasileira por Satélite. Disponível em: http://www.obt.inpe.br/OBT/assuntos/programas/amazonia/prodes. Acesso em: 22 abr. 2020.

KASSAM, A.; DERPSCH, R.; FRIEDRICH, T. Global achievements in soil and water conservation: the case of conservation agriculture. International Soil and Water Conservation Research, v. 2, n. 1, p. $5-13,2014$.

KROEGER, T.; CASEY, F. An assessment of market-based approaches to providing ecosystem services on agricultural lands. Ecological Economics, v. 64, n. 2, p. 321-332, 2007.

LUTZENBERGER, J. A. O absurdo da agricultura. Estudos Avançados, v. 15, n. 43, p. 61-74, 2001.

MAZOYER, M.; ROUDART, L. História das agriculturas no mundo: do neolítico à crise contemporânea. Brasília, DF: NEAD, 2010.

MEDINA, G. da S. Where are governments leading their agricultural sectors? Comparative lessons from agri-environmental measures promoted in the U.S., Europe and Brazil. Estudos Sociedade e Agricultura, v. 27, n. $1,2019$.

MILLENNIUM ECOSYSTEM ASSESSMENT BOARD. Ecosystems and Human Well-being: a framework for assessment. Washington, DC.: Island Press, 2003.

MITCHELL, F. C. Conditions for mechanization in Europe. In: MEIJI, J. L. (Ed.). Mechanization in agriculture. Amsterdan: [North Holland Publishing Company, 1960]. 
MOLIN, J. P. Tendências da agricultura de precisão no Brasil. In: CONGRESSO BRASILEIRO DE AGRICULTURADE PRECISÃO, 1., 2004, Piracicaba. Anais... Piracicaba: Escola Superior de Agricultura "Luiz de Queiroz", 2004. p. 1-10.

MOONEY, H. A.; EHRLICH, P. R. Ecosystem services: a fragmentary history. In: DAILY, G. C. (Ed.). Nature's services: societal dependence on natural ecosystems. Washington, DC.: Island Press, 1997.

MULDER, K.; COSTANZA, R.; ERICKSON, J. The contribution of built, human, social and natural capital to quality of life in intentional and unintentional communities. Ecological Economics, v. 59, n. 1, p. 13-23, 2006.

NOBRE, M.; AMAZONAS, M. de C. Desenvolvimento sustentável: a institucionalizaçao de um conceito. Brasília, DF: Ministério do Meio Ambiente: Instituto Brasileiro do Meio Ambiente e dos Recursos Naturais Renováveis, 2002.

PAPY, F. Praticabilite du milieu et itineraires techniques. Bulletin Technique d'Information, p. 370-372, Mai/Juin/Juillet/Août., 1982.

PARRON, L. et al. Avaliação de serviços ecossistêmicos em sistemas agrossilvipastoris. Revista Iberoamerica de Economia Ecológica, v. 30, n. 1, 2019.

PASCHOAL, A. D. Pragas, praguicidas e a crise ambiental: problemas e soluções. Rio de Janeiro: Fundação Getúlio Vargas, 1979.

PEARCE, D. W.; TURNER, R. K. Economics of natural resources and the environment. Baltimore: The Johns Hopkins University Press, 1990.

PETRUCCELLI, J. L. Café, escravidão e meio ambiente - o declínio de Vassouras na virada do século XIX. Estudos Sociedade e Agricultura, v. 2, n. 2, p. 79-91, 1994.

PRADO, R. B. R. B. et al. Current overview and potential applications of the soil ecosystem services approach in Brazil. Pesquisa Agropecuária Brasileira, v. 51, p. 1021-1038, 2016.

PRADO JUNIOR, C. História econômica do Brasil. 20. ed. São Paulo: Editora Brasiliense, 1977.

PROJETO MAPBIOMAS. Coleção 4.0 da Série Anual de Mapas de Cobertura e Uso de Solo do Brasil. [s.1.] , 2020.

RATES, E. et al. Soil erosion. [sl.: s.n.], 2016.

REMY, J. C.; MARIN LAFLECHE, A. L'entretien organique des terres. Cout d'une politique de l'humus. Entreprises Agricoles, v. 84, 1976.

ROMEIRO, A. R. O agronegócio será ecológico. In: BUAINAIN, A. M. et al. (Ed.). O mundo rural no Brasil do século XXI: a formação de um novo padrão agrário e agrícola. Brasília, DF: Embrapa, 2014.

ROMEIRO, A. R. Meio ambiente e dinâmica de inovações na agricultura. São Paulo: Annablume, 1998.

ROMEIRO, A. R. O modelo euro-americano de modernização agrícola. Nova Economia, v. 2, n. 2, p. 175-197, 1991.

ROMEIRO, A. R.; ABRANTES, F. J. Meio ambiente e modernização agrícola. Revista Brasileira de Geografia, v. 43, n. 1, p. 3-46, 1981. 
SANTANA, C. A. M. et al. Política agrícola: avanços e retrocessos ao longo de uma trajetória positiva. In: BUAINAIN, A. M. et al. (Ed.). O mundo rural no Brasil do século 21: a formação de um novo padrão agrário e agrícola. Brasília, DF: Embrapa, 2014.

SANTOS, H. G. dos et al. (Ed.). Sistema Brasileiro de Classificação de Solos. 2. ed. Rio de Janeiro: Embrapa Solos, 2006. 306 p.

SCANTIMBURGO, A. O desmonte da agenda ambiental no governo Bolsonaro. Perspectivas, Revista de Ciências Sociais, v. 52, p. 103-117, 2018.

SEBILlotTe, M. La monoculture de cereales. Bles/Bles? - Mais/Mais? Entreprises Agricoles, v. 67, Juin. 1975.

SEBILlOTTE, M. Pratiques des agriculteurs et evolution de la fertilite du milieu - elements pour un jugement des systemes de culture. Bulletin Technique d'Information, p. 370-372, Mai/Juin/Juillet/Août. 1982.

SEBILLOTTE, M.; BOURGEOIS, A. Reflexion sur l'evolution contemporaine des exploitations agricoles. Economie Rurale, v. 1126, 1978.

SEDIYAMA, T. (Ed.). Tecnologias de produção e usos da soja. Londrina: Mecenas, 2009. 314 p.

STEGER, C. et al. Ecosystem services as boundary objects for transdisciplinary collaboration. Ecological Economics, v. 143, p. 153-160, 2018.

SWIFT, M. J.; IZAC, A. N.; NOORDWIJK, M. van. Biodiversity and ecosystem services in agricultural landscapes - are we asking the right questions? Most, v. 104, p. 113-134, 2004.

TRIGUEIRO, A. 15 pontos para entender os rumos da desastrosa política ambiental no governo Bolsonaro. G1 - Natureza: Blog do André Trigueiro, jun. 2019.

VIEIRA FILHO, J. E. R.; GASQUES, J. G. Agricultura, transformação produtiva e sustentabilidade. Brasília, DF: IPEA, 2016.

ZHANG, W. et al. Ecosystem services and dis-services to agriculture. Ecological Economics, v. 64, n. 2 , p. 253-260, 2007.

ZIMMER, A. H. et al. Degradação, recuperação e renovação de pastagens. Campo Grande, MS: Embrapa Gado de Corte, 2012. 46 p. (Embrapa Gado de Corte. Documentos, 189). 
